\title{
Research on the Impact of Logistics Technology Progress on Employment Structure Based on DEA-Malmquist Method
}

\author{
Xiao-qing Lei, ${ }^{1}$ Jia-jia Yang $\mathbb{D}^{2}{ }^{2}$ Jian-bo Zou, ${ }^{1}$ and Mei-er Zhuang ${ }^{3}$ \\ ${ }^{1}$ School of Business, Guangdong University of Foreign Studies, Guangzhou 510006, China \\ ${ }^{2}$ Department of Public Policy, King's College London, London WC2R 2LS, UK \\ ${ }^{3}$ School of Business, Guangdong University of Foreign Studies, Guangzhou 510000, China \\ Correspondence should be addressed to Jia-jia Yang; 1298256371@qq.com
}

Received 20 August 2020; Revised 3 September 2020; Accepted 4 September 2020; Published 15 September 2020

Academic Editor: Weilin Xiao

Copyright ( $) 2020$ Xiao-qing Lei et al. This is an open access article distributed under the Creative Commons Attribution License, which permits unrestricted use, distribution, and reproduction in any medium, provided the original work is properly cited.

In recent years, with the vigorous development of e-commerce, the logistics industry has also developed rapidly and has gradually become one of China's important industries. This paper takes 49 listed companies in the logistics industry in China as the research object and uses the DEA-Malmquist index method to measure the technology progress index of the logistics industry based on their panel data for a total of 10 years from 2008 to 2017. In this way, this article explores the impact of technological progress in the logistics industry and provides a reference for solving the contradiction of employment structure in China

\section{Introduction}

After more than 30 years of development, the logistics industry not only has become a pillar industry of China's national economy but also serves as an important modern service. In 2013, the size of China's logistics market surpassed that of the United States for the first time. Since then, China has become a veritable logistics power country. However, the development quality of China's logistics industry is generally not high, and its dependence on factor inputs is strong. Because its development model is extensive, the logistics industry has always been regarded as a laborintensive industry. In recent years, modern logistics equipment technologies such as automated three-dimensional warehouses, automatic sorting equipment, and smart logistics equipment have developed rapidly. Information technologies such as the Internet of Things, big data, and cloud computing have been widely used in the logistics industry. The automation level of the logistics industry has been continuously improved, showing that capital is obviously deepening and technological progress is accelerating. This indicates that China's logistics industry will undergo a profound technological change, which will not only changes the development model of the logistics industry but also have an significant impact on employment in the logistics industry.

Technological progress has a dual effect on employment, namely, creation effect and shock effect. From the previous literature, it can be seen that most scholars mainly study the relationship between technological progress and employment and seldom analyze the degree of matching between technological progress and employment structure. Therefore, exploring the mechanism of technological progress in the logistics industry on employment and finding the best matching relationship between them has important practical and theoretical significance for the long-term development of the logistics industry. This article will explore the impact of technological progress in the logistics industry on the employment structure and find a balance between the two, providing a reference for scientifically formulating technological progress and employment policies in China's logistics industry.

\section{Literature Review}

For the research on the impact of technological progress in the logistics industry on the employment structure, this section will summarize from three perspectives, namely, the 
perspective of industrial structure, the perspective of biased technological progress, and the perspective of rising unemployment.

Technological progress can indirectly drive changes in the employment structure by causing adjustments to the industrial structure. Therefore, some scholars have tried to systematically analyze the impact of technological progress and employment structure from the perspective of industrial structure. For example, Xiong and Zhu [1] started from the aspect of industrial structure changes and discussed the relationship among technological progress, changes in the three industrial structure layouts, and employment, and they claimed that changes in the industrial structure layout are negative for China's employment, which will increase the number of the unemployed. Additionally, Jiang [2] found that technological progress will first affect the change of industrial structure to a certain extent and then indirectly affect the change of employment status. Bo and Wen [3] used the data envelopment analysis method to divide the industry into resource-intensive, labor-intensive, capital-intensive, and technology-intensive sectors based on the total factor productivity of the industrial sector and analyzed the impact of technological progress on the employment of different industrial sectors in China. Furthermore, some scholars also conducted empirical analysis on the relationship between technological progress and employment structure based on the perspective of technological progress. For example, Srour et al. [4] and Buera et al. [5] used the number of patents and the internal $\mathrm{R} \& \mathrm{D}$ expenditure of enterprises to replace the indicators of technological progress and found that technological innovation promoted changes in the employment structure of the labor market. Moreover, Berman et al. [6] studied the application of new technologies such as computers in the United States in the 1980s, and Spitz-Oener [7] conducted empirical research based on sample data from the former Federal Republic of Germany from 1979 to 1999 . The results showed that technological progress would significantly increase the relative demand for high-level personnel. Similarly, Kaplan [8] also believes that the faster the development of advanced information technology such as AI, the more types of low-skilled jobs to be replaced by information and automation equipment. In addition, some scholars have studied the relationship between technological progress and employment structure from the perspective of unemployment rate. For instance, Zhu and $\mathrm{Li}$ [9] used artificial intelligence as the research object, and found that some employees with low academic qualifications and first-line production type will be replaced by artificial intelligence technology. Besides, Mincer and Danninger [10] empirically studied the relationship between technological progress and the structure of employment skills from the perspective of the unemployment rate based on the sample statistics of the United States from 1970 to 1995. The results showed that the increase in technological progress would lead to the increasing unemployment of lowskilled personnel. To be more specific, through research Acemoglu [11] argued that the technological progress contributes to the simultaneous rises of unemployment in both low-skilled workers and high-skilled staff. Apart from that, Katz and Murphy [12] argued that high-skilled skewed technological progress will lead to an increasingly relative demand for high-skilled personnel, but at the same time, it will reduce the relative demand for low-skilled labor.

In summary, related research on this topic mainly presents the following characteristics: first, it is mainly based on the entire national economic sector or industry. In other words, manufacturing is the study background, and there is a lack of relevant research from the microenterprises or industry level; second, empirical analysis is mostly based on provincial panel data, and many studies use sample data before 2010, while technological progress has changed rapidly, especially in recent years, so the current level of technological progress will be largely ignored. Third, the employment structure should reflect changes in the relative numbers of different types of labor, including education level, gender ratio, professional structure, skill training, and age ratio. The most significant feature is the employment changes of highly skilled and low-skilled personnel in terms of their quantity and structure. In order to make up for the limitations of previous research, this article starts from a microperspective. Based on the panel data of 49 listed companies in China's logistics industry, this study on the relationship between technological progress and employment structure can fill up some of the gaps in the field of research, which has strong practical significance.

\section{DEA-Malmquist Method}

Rolf Fare proposed the Malmquist index method in 1994 on the basis of the nonparametric linear programming method. This new method is to measure the total factor productivity (TFP) index and then to study the technological progress indicators. Meanwhile, the total factor productivity index was effectively decomposed into a technical efficiency index and a technology change index based on a distance function for the first time:

$$
\begin{aligned}
M_{0}^{t+1} & =\left[\frac{D^{t}\left(x_{0}^{t+1}, y_{0}^{t+1}\right)}{D^{t}\left(x_{0}^{t}, y_{0}^{t}\right)} \times \frac{D^{t+1}\left(x_{0}^{t+1}, y_{0}^{t+1}\right)}{D^{t+1}\left(x_{0}^{t}, y_{0}^{t}\right)}\right]^{1 / 2} \\
& =\frac{D^{t+1}\left(x_{0}^{t+1}, y_{0}^{t+1}\right)}{D^{t}\left(x_{0}^{t}, y_{0}^{t}\right)}\left[\frac{D^{t}\left(x_{0}^{t+1}, y_{0}^{t+1}\right)}{D^{t+1}\left(x_{0}^{t+1}, y_{0}^{t+1}\right)} \times \frac{D^{t}\left(x_{0}^{t}, y_{0}^{t}\right)}{D^{t+1}\left(x_{0}^{t}, y_{0}^{t}\right)}\right]^{1 / 2} .
\end{aligned}
$$

Under the condition of constant return to scale, TFP can be decomposed into the technical progress index (tech) and technical efficiency index (effch):

$$
\begin{aligned}
M_{0}\left(x^{t+1}, y^{t+1}, x^{t}, y^{t}\right)= & {\left[\frac{D_{0}^{t+1}\left(x^{t+1}, y^{t+1}\right)}{D_{0}^{t+1}\left(x^{t}, y^{t}\right)} \times \frac{D_{0}^{t}\left(x^{t+1}, y^{t+1}\right)}{D_{0}^{t}\left(x^{t}, y^{t}\right)}\right]^{1 / 2} } \\
& \times \frac{D_{0}^{t+1}\left(x^{t+1}, y^{t+1}\right)}{D_{0}^{t+1}\left(x^{t}, y^{t}\right)}=\text { effch }{ }^{*} \text { tech. }
\end{aligned}
$$

If the technical efficiency index effch $>1$, it indicates that the technical efficiency is improved, and vice versa. This 
decomposition can clearly understand the changes and trends of total factor productivity, further analyzes the factors that lead to changes, explores the influence coefficient of each factor, and then explores the focus and improvement space for its progress and growth. Through further exploration of technical efficiency, the changes can be further decomposed into pure technical efficiency and scale efficiency:

$$
\begin{aligned}
M_{0}\left(x^{t+1}, y^{t+1}, x^{t}, y^{t}\right)= & {\left[\frac{D_{0}^{t+1}\left(x^{t+1}, y^{t+1}\right)}{D_{0}^{t+1}\left(x^{t}, y^{t}\right)} \times \frac{D_{0}^{t}\left(x^{t+1}, y^{t+1}\right)}{D_{0}^{t}\left(x^{t}, y^{t}\right)}\right]^{1 / 2} } \\
& \times \frac{D_{0}^{t+1}\left(x^{t+1}, y^{t+1}\right)}{D_{0}^{t+1}\left(x^{t}, y^{t}\right)}=\text { pech }^{*} \text { sech }^{*} \text { tech. }
\end{aligned}
$$

This article uses the DEA-Malmquist method for analysis, mainly for the following reasons: first, the production model function corresponding to the DEA-Malmquist index method does not need to be uniquely determined, which can effectively avoid the problem of inaccurate measurement results caused by improper model processing. Secondly, the Malmquist index method does not require various research hypotheses, it can better reflect the true situation of the current market, and the calculated results are more convincing. Finally, the results calculated by this method can not only help explain the differences in economic development levels but also clearly know how to effectively increase productivity levels through the decomposition of total factor productivity. Compared with traditional estimation methods, various factors affecting productivity can be considered in many aspects, including management, technical level, resource allocation, and technological mastery. Traditional estimation methods can only estimate a specific value but cannot reflect these influencing factors play a role in productivity improvement.

However, due to differences in research objects or perspectives, different scholars have different opinions and choices on input variables and output variables, which leads to the various selections of input and output elements when they use the DEA-Malmquist index method to measure the total factor productivity index and its decomposition. Based on previous results and combining the characteristics of China's logistics industry, this paper selects input elements from the perspectives of equipment input, human capital, and business operations. They are net fixed assets, total wages, and operating costs as input indicators, while output indicators are main business income, using DEAP2.1 software to measure the technological progress index of the logistics industry.

\section{Empirical Analysis of Technological Progress in China's Logistics Industry on Employment Structure}

This chapter uses the statistical data of 49 listed companies in the logistics industry of Shanghai and Shenzhen A shares from 2009 to 2017 to conduct an empirical analysis of the relationship between technological progress and employment structure in China's logistics industry through research methods such as unit root test, cointegration analysis, and regression analysis.

4.1. Construction of Regression Model. Based on the theory of biased technological progress and combined with the status quo of China's logistics industry, relevant indicators are selected to construct an econometric regression model:

$$
\begin{aligned}
& y 1=C+\alpha 1 \times 1+\beta 1 \times 2+\gamma 1 \times 3+\delta 1 \times 4, \\
& y 2=C+\alpha 2 x 1+\beta 2 \times 2+\gamma 2 \times 3+\delta 2 \times 4 .
\end{aligned}
$$

Among them, the explained variables $y 1$ and $y 2$, respectively, represent the proportion of personnel with a college degree or above and the proportion of nonproduction personnel. The explanatory variable $x 1$ is the technological progress of the logistics industry replaced by the technological progress index; at the same time, three control variables $(x 2, x 3$, and $x 4)$ are added to improve the interpretation of the regression model. They are the size of the enterprise measured by the main business income and the employee training structure replaced by per capita training investment and salary structure represented by per capita salary of employees.

\subsection{Variable Description and Data Source and Processing}

\subsubsection{Variable Description}

(1) Selection of Explained Variables. For the definition of the explanatory variable indicators, there are currently two main methods of classification: the first is to regard the proportion of persons with a college degree or above as high-skilled labor, and those below college are low-skilled labor; that is, the observable education premium is used to reflect the skill gains; The second is to regard nonproductive labor as highskilled labor, and those engaged in productive labor are lowskilled labor. The second classification method is widely used in the study of wage differences in industrial enterprises above designated size or large- and medium-sized industrial enterprises. For example, the scientific and technological personnel of large- and medium-sized manufacturing enterprises used this way as a substitute index for skilled labor in manufacturing, and the labor service fees represent the wage level of skilled labor. In previous studies, only one of these methods was often selected for index measurement, which lacked comprehensiveness to a certain extent. Therefore, this article uses both college degree and above and nonproductive labor as substitute variables for high-skilled labor, which not only fully reflects the changes in the structure of high- and low-skilled labor in the industry but also enriches the related information in the research through comparative analysis.

(2) Selection of Explanatory Variables. In the previous literature, explanatory variables usually used indicators such as total factor productivity index, technological progress index, 
$R \& D$, number of patents granted, and value of machinery and equipment per capita. Since this article is based on listed companies in the logistics industry as the research object on the basis of combining industry conditions and considering the availability of data and the objectivity of the research, this paper use the technology progress index measured by the DEA-Malmquist index method to represent the technology progress, and it can fully reflect the current situation of China's logistics industry through selecting reasonable input-output indicators.

(3) Selection of Control Variables. In order to accurately reflect the impact of technological progress in the logistics industry and control other factors that may affect the structure of employment skills, this paper takes enterprise scale, training structure, and salary structure as the control variables of the model. Generally speaking, the larger the scale of an enterprise, the more manpower and material resources are needed in order to improve production efficiency, so the demand for highly skilled talents will increase relatively. In addition, training investment is also an indispensable factor in the development of a company. Good training can improve the overall quality and abilities of the company's employees and increase the company's production efficiency, which in turn will attract some external talents. Finally, this article uses per capita wage to replace the wage structure. Except for a good platform or a complete training system, high wages will also attract new blood. At the same time, companies with higher wage levels tend to have more powerful company's strength, promising development prospects, and higher management level, and the greater demand for high-level talents In order to eliminate the dimensional relationship between variables and make the data comparable, this article standardizes the analysis data of all variables before the empirical test, as shown in Table 1.

4.2.2. Data Source and Processing. Based on the definition and classification of the logistics industry, there are currently 115 listed logistics companies in China. In order to ensure the validity and accuracy of the data and research results, this article needs to eliminate some noncompliant companies. This article exclude companies that do not meet the conditions in accordance with the following principles: first, companies with insufficient data years; second, companies whose annual report data classification rules differ significantly from those of other companies; third, companies that disclose data between 2008 and 2017 years; fourth, companies that have too few staff and do not have required indicator data. Finally, there are 49 listed companies in the logistics industry that meet the needs of this study, including 8 in the air transport industry, 21 in the road transport industry, 3 in the railway transport industry, and 15 in the water transport industry, There is one firm in each industry, namely, loading and unloading industry transportation agency, warehousing, and business service industry as shown in Table 2.

\subsection{Empirical Analysis}

4.3.1. Unit Root Test. Before performing regression analysis on panel sequence data, it is necessary to test the stationarity of the research data first to determine whether it is a stationary sequence of the same order. Among the methods for testing the stationarity of panel data, the commonly used method is unit root testing. This paper adopts the unit root test and uses the three methods of LLC, ADF-Fisher, and PPFisher to analyze the stability of panel data (see Table 3).

It can be found from Tables 2-4 that the results of $X 2$ and $X 4$ in the ADF-Fisher test are not significant, and the results of $X 4$ in the PP-Fisher test are not significant, which indicates that the test values of these variables cannot reject the null hypothesis with existence of panel unit roots. The firstorder difference of each variable is significant at the $1 \%$ significance level, indicating that there is no panel unit root.

4.3.2. Cointegration Test. In addition, in order to ensure the long-term stability between the variables in this model and effectively prevent spurious regression, it is necessary to conduct a cointegration test on each variable. Based on the research of previous scholars, this paper uses the Pedroni test and Kao test at the same time and uses Eviews9.0 analysis software to do the cointegration analysis test for each research variable. The specific inspection results are shown in Table 4.

From the results of the cointegration test in Table 4, we can find that the Pedroni test's test statistic value divided by the panel ADF test value in model (1) is significant at the 5\% significance level, and the other test values are all at $1 \%$ significant. The test statistics of the Kao test are significant at the $5 \%$ and $1 \%$ significance levels, respectively. Both test methods are said to obviously reject the null hypothesis. This shows that there is a cointegration relationship between the explanatory variable and the explained variable, which meets the stability requirements of time or panel data, and there is a long-term stable relationship between the variables, which is suitable for regression analysis.

4.4. Regression Analysis. The estimation of panel data model usually adopts the individual fixed effect model or individual random effect model. Therefore, before performing regression analysis, performing the Hausman test to determine which regression model should be based on its test results. The test results are shown in Table 5; that is, the $P$ values in model (1) and model (2) are both less than 0.05 , significantly rejecting the null hypothesis and indicating that the fixedeffects model should be used for regression analysis.

In addition, considering that there may be heteroscedasticity problems in the model, the regression results of the model seem not robust. Therefore, the "fixed effect model + robust standard error" is adopted; that is, the panel calibration standard error (PCSE) estimates model (1) and the model (2). The regression results of the model are shown in Table 6. 
TABle 1: Index selection and data sources.

\begin{tabular}{|c|c|c|c|}
\hline Research variables & First-level indicator & Metrics & Data sources \\
\hline Explanatory variable $(X 1)$ & $\begin{array}{l}\text { Technological progress in the } \\
\text { logistics industry }\end{array}$ & Technology progress index $(X 1)$ & $\begin{array}{c}\text { Cathay pacific } \\
\text { database }\end{array}$ \\
\hline Explained variables $(Y 1, Y 2)$ & Employment skill structure & $\begin{array}{l}\text { Proportion of employees with } \\
\text { college degree and above }(Y 1)\end{array}$ & $\begin{array}{c}\text { Listed company } \\
\text { annual report }\end{array}$ \\
\hline \multicolumn{4}{|l|}{$\begin{array}{l}\text { Proportion of nonproduction } \\
\text { personnel }(Y 2)\end{array}$} \\
\hline Control variable $(X 2, X 3, X 4)$ & Enterprise size $(X 2)$ & Main business income & $\begin{array}{c}\text { Cathay pacific } \\
\text { database }\end{array}$ \\
\hline Training structure $(X 3)$ & Training investment per employee & Listed company annual report & \\
\hline Salary structure $(X 4)$ & Salary per employee & Listed company annual report & \\
\hline
\end{tabular}

TABLE 2: Sample enterprises.

\begin{tabular}{|c|c|c|}
\hline Enterprise code & Company abbreviation & Industry \\
\hline 000088 & Yantian Port & Road transport industry \\
\hline 000089 & Shenzhen Airport & Air transport industry \\
\hline 000099 & CITIC Haizhi & Air transport industry \\
\hline 000429 & Guangdong Expressway A & Road transport industry \\
\hline 000507 & Zhuhai Port & Water transport industry \\
\hline 000582 & Beibu Gulf Port & Water transport industry \\
\hline 000828 & Dongguan Holdings & Road transport industry \\
\hline 000885 & City Development Environment & Road transport industry \\
\hline 000900 & Modern Investment & Road transport industry \\
\hline 000905 & Xiamen Port & Water transport industry \\
\hline 002010 & Chuanhua Zhilian & Business service industry \\
\hline 002040 & Nanjing Port & Water transport industry \\
\hline 600009 & Shanghai Airport & Air transport industry \\
\hline 600012 & Anhui Expressway & Road transport industry \\
\hline 600017 & Rizhao Port & Water transport industry \\
\hline 600020 & Zhongyuan Expressway & Road transport industry \\
\hline 600026 & COSCO Shipping Energy & Water transport industry \\
\hline 600029 & Southern Airline & Air transport industry \\
\hline 600033 & Fujian Express & Road transport industry \\
\hline 600035 & Chutian Expressway & Road transport industry \\
\hline 600106 & Chongqing Road and Bridge & Road transport industry \\
\hline 600115 & Eastern Airlines & Air transport industry \\
\hline 600119 & Yangtze River Investment & Road transport industry \\
\hline 600125 & Iron Dragon Logistics & Railway transportation industry \\
\hline 600190 & Port of Jinzhou & Water transport industry \\
\hline 600221 & HNA Holdings & Air transport industry \\
\hline 600269 & Ganyue Expressway & Road transport industry \\
\hline 600270 & Sinotrans Development & Handling \\
\hline 600279 & Chongqing Port and Kowloon & Water transport industry \\
\hline 600317 & Yingkou Port & Water transport industry \\
\hline 600350 & Shandong Expressway & Road transport industry \\
\hline 600368 & Wuzhou Transportation & Road transport industry \\
\hline 600377 & Nanjing-Shanghai Expressway & Road transport industry \\
\hline 600428 & COSCO Haite & Water transport industry \\
\hline 600548 & Shenzhen Expressway & Road transport industry \\
\hline 600561 & Jiangxi Changyun & Road transport industry \\
\hline 600575 & Wanjiang Logistics & Water transport industry \\
\hline 600611 & Public Transportation & Road transport industry \\
\hline 600650 & Jinjiang Investment & Xiamen airport \\
\hline 600662 & Johnson \& Johnson Holdings & Daqin Railway \\
\hline 600676 & Delivery Shares & Lianyungang \\
\hline 600717 & Tianjin Harbor & Air China \\
\hline 600787 & China Reserve & Guangzhou-Shenzhen Railway \\
\hline 600798 & Ningbo Shipping & \\
\hline 600897 & Xiamen Airport & Air transport industry \\
\hline 601006 & Daqin Railway & Railway transportation industry \\
\hline 601008 & Lianyungang & Water transport industry \\
\hline 601111 & Air China & Air transport industry \\
\hline 601333 & Guangzhou-Shenzhen Railway & Railway transportation industry \\
\hline
\end{tabular}


TABLE 3: Unit root test results.

\begin{tabular}{lccc}
\hline Variables & LLC & ADF-Fisher & PP-Fisher \\
\hline$Y 1$ & $-4.29407^{* * *}$ & $132.633^{* *}$ & $159.769^{* * *}$ \\
$\Delta Y 1$ & $-16.7506^{* * *}$ & $260.739^{* * *}$ & $381.058^{* * *}$ \\
$Y 2$ & $-17.5232^{* * *}$ & $156.507^{* * *}$ & $128.048^{* *}$ \\
$\Delta Y 2$ & $-24.5752^{* * *}$ & $282.135^{* * *}$ & $348.022^{* * *}$ \\
$X 1$ & $-14.7307^{* * *}$ & $227.555^{* *}$ & $280.123^{* * *}$ \\
$\Delta X 1$ & $-24.5421^{* * *}$ & $341.662^{* * *}$ & $529.502^{* * *}$ \\
$X 2$ & $-3.38952^{* * *}$ & 101.830 & $152.253^{* * *}$ \\
$\Delta X 2$ & $-5.38774^{* * *}$ & $177.549^{* * *}$ & $220.121^{* * *}$ \\
$X 3$ & $-8.32027^{* * *}$ & $153.784^{* * *}$ & $205.803^{* * *}$ \\
$\Delta X 3$ & $-30.8146^{* * *}$ & $272.010^{* * *}$ & $306.273^{* * *}$ \\
$X 4$ & $-2.64603^{* * *}$ & 92.6991 & 110.325 \\
$\Delta X 4$ & $-20.4947^{* * *}$ & $268.751^{* * *}$ & $379.493^{* * *}$ \\
\hline
\end{tabular}

Note. ${ }^{*},{ }^{* *}$, and ${ }^{* * *}$, respectively, indicate significant at the $10 \%$ level, significant at the $5 \%$ level, and significant at the $1 \%$ level.

TABLE 4: Cointegration test results.

\begin{tabular}{|c|c|c|c|}
\hline & Statistics & Model (1) & Model (2) \\
\hline \multirow{9}{*}{$\begin{array}{l}\text { Pedroni } \\
\text { test }\end{array}$} & Panel v & $\begin{array}{c}-2.841026 \\
(0.9978)\end{array}$ & $\begin{array}{c}-3.668634 \\
(0.9999)\end{array}$ \\
\hline & Panel rho & $6.335616(1.0000)$ & $5.741516(1.0000)$ \\
\hline & Panel PP & $\begin{array}{c}-2.994059 \\
(0.0014)\end{array}$ & $\begin{array}{c}-3.768672 \\
(0.0001)\end{array}$ \\
\hline & Panel ADF & -2.187057 & -3.269702 \\
\hline & rance his & $(0.0144)$ & $(0.0005)$ \\
\hline & Group rho & $8.957185(1.0000)$ & $9.126544(1.0000)$ \\
\hline & Group PP & $\begin{array}{c}-11.45461 \\
(0.0000)\end{array}$ & $\begin{array}{c}-11.36620 \\
(0.0000)\end{array}$ \\
\hline & Group & -5.795894 & -4.448520 \\
\hline & $\mathrm{ADF}$ & $(0.0000)$ & $(0.0000)$ \\
\hline Kao test & $\mathrm{ADF}$ & $\begin{array}{c}-1.931086 \\
(0.0267)\end{array}$ & $\begin{array}{c}-4.780048 \\
(0.0000)\end{array}$ \\
\hline
\end{tabular}

TABLE 5: Hausman test.

\begin{tabular}{lcc}
\hline Detection value & Model (1) & Model (2) \\
\hline Chi-sq. & 7.225 & 10.442 \\
Prob. & 0.0245 & 0.0336 \\
Result & FE & FE \\
\hline
\end{tabular}

Note. Chi-sq. means chi-square value, FE means individual fixed effect, and $\mathrm{RE}$ means individual random effect.

(1) Technological progress is positively correlated with the proportion of personnel with a college degree or above and is significant at a significance level of 5\%; technological advancement positively and significantly affects the proportion of nonproductive personnel at a significance level of $10 \%$ ratio. This shows that with the continuous investment in technology in China's logistics industry, the relative demand for high-skilled labor is increasing, and there is a certain degree of skill-biased technological progress in China's logistics industry.

(2) There is a positive correlation between the scale of the enterprise and the proportion of employees with a college degree or above, and it is significant at the $1 \%$ significance level, which indicates that the expansion of the scale of logistics enterprises will lead to a significant increase in the proportion of employees with a high degree of education. Generally speaking, the higher the management level of the company, the more the resources it has. The more attractive it is to the new generation of young people, the faster costs can be obtained. At the same time, the scale of the enterprise and the proportion of nonproductive employees show a negative correlation. It is significant at the $1 \%$ significance level, which shows that the expansion of the logistics enterprise scale will reduce the growth of the proportion of nonproductive employees.

(3) The relationship between the training structure and the proportion of personnel with college degree or above and the proportion of nonproductive employees is not significant, indicating that the training investment in Chinese logistics companies does not actually affect the number of highly skilled personnel and nonproductive personnel. To what extent the increase in quantity has contributed to the increase, it can also be seen from the other hand that China's logistics industry still has major problems in the construction of training system and training input and output. The training mechanism needs to be improved as soon as possible to improve the efficiency of enterprise input and output.

(4) The $10 \%$ significance level of the wage structure has a positive and significant impact on the proportion of nonproductive personnel, and the coefficient of the wage structure is 0.463 , but there is no obvious significant relationship with the proportion of personnel with a college degree or above. This shows that the increase in employee wages will significantly increase the proportion of high-educated and management personnel in the company.

4.5. Treatment of Endogenous Problems. From the results of Hausman's test, we can know that the regression of panel data in this paper uses an individual fixed-effects model, and the consistency of the model estimates requires that the explanatory variables are independent of the random error term.

This article will use the method of lagging all the explanatory variables in the econometric model to deal with the endogenous problem and still use the individual fixedeffects model to estimate. However, since the current data of listed companies in the logistics industry do not have statistics for 2018, the data of all the explained variables are preceded by a model regression. This approach can not only effectively reduce the estimation bias caused by the possible endogenous problems of explanatory variables but also effectively reflect the time lag effect of technological progress and other explanatory variables on the employment skill structure. The specific regression results are shown in Tables 4-6.

The results show that compared with the regression results of individual fixed effects without considering endogeneity, the relationship between technological 
TABLE 6: Model regression analysis results.

\begin{tabular}{|c|c|c|c|c|}
\hline \multirow{2}{*}{$\begin{array}{l}\text { Model } \\
\text { Research variables }\end{array}$} & \multirow{2}{*}{$\begin{array}{c}\text { Model (1) } \\
\begin{array}{c}\text { Proportion of employees } \\
\text { with college degree and } \\
\text { above }(Y 1)\end{array}\end{array}$} & \multirow{2}{*}{$\begin{array}{c}\text { Model (2) } \\
\text { Percentage of } \\
\text { nonproductive } \\
\text { personnel }(Y 2)\end{array}$} & \multicolumn{2}{|c|}{$\begin{array}{c}\begin{array}{c}\text { Endogenous treatment (explanatory variables lag one } \\
\text { period) }\end{array}\end{array}$} \\
\hline & & & $\begin{array}{c}\text { Proportion of employees } \\
\text { with college degree and } \\
\text { above }(Y 1)\end{array}$ & $\begin{array}{l}\text { Percentage of } \\
\text { nonproductive } \\
\text { personnel }(Y 2)\end{array}$ \\
\hline Constant $(C)$ & $0.440194^{* * *}(0.016699)$ & $0.333155^{* * *}(0.013669)$ & $0.418368^{* * *}(0.014612)$ & $0.331739^{* * *}(0.00925)$ \\
\hline $\begin{array}{l}\text { Technical surgery } \\
\text { progress }(X 1)\end{array}$ & $0.022331^{* *}(0.081772)$ & $0.117531^{*}(0.067472)$ & $0.092411^{* * *}(0.031450)$ & $0.092193^{*}(0.066930)$ \\
\hline Enterprise size $(X 2)$ & $0.458099^{* * *}(0.144343)$ & $-0.298354^{* * *}(0.095644)$ & $0.441151^{* * *}(0.141801)$ & $-0.181941^{* *}(0.087253)$ \\
\hline Training stru & $0.058520(0.155537)$ & $-0.294763(0.221910)$ & $0.109641(0.148890)$ & $0.005133(0.095176)$ \\
\hline Salary s & $0.235782(0.159337)$ & $0.462559 *(0.247141)$ & $0.061670(0.148312)$ & $-0.131753(0.096665)$ \\
\hline Adjusted $R^{2}$ & 0.821132 & 0.726680 & 0.821009 & 0.712306 \\
\hline
\end{tabular}

Note. ${ }^{*}$ Represents the $10 \%$ significance level, ${ }^{* *}$ represents the $5 \%$ significance level, and ${ }^{* * *}$ represents the $1 \%$ significance level.

progress and enterprise size and employment structure all presents a significant positive correlation. However, the number and significance level of the estimated coefficients of the above variables have decreased to varying degrees due to the decrease in sample observations, which indicates that the significantly positive estimated coefficients of technological progress and firm size in the econometric regression equation are not affected by the endogenous problems caused by the correlation between the current explanatory variables and the current residuals influences.

4.6. Empirical Analysis from the Perspective of Industry Segments. Based on China's specific conditions, different subsectors of the logistics industry have their own characteristics in terms of input and output of technological progress and employment structure. Therefore, in order to better promote the development of the logistics industry, a clear understanding of the differences and characteristics of the technological progress and employment structure of each logistics subindustry will help the progress and development of the logistics industry, and also help clarify government's policy direction. The most important thing is that the classification of logistics companies enables companies to position themselves more clearly and enable them to give full play to their advantages. Therefore, this section analyzes the relationship between technological progress and employment structure from the perspective of subindustry. However, because the index and related data that do not meet the research requirements of this article are eliminated at the beginning of the data processing stage, this article only selects the three major subdivisions, namely, the air transport industry, road transport industry, and water transport industry to analyze and compare after considering the sample data volume.

First, the Hausman test is performed on different measurement models of each subindustry to determine which model to choose for regression analysis. The specific analysis results are shown in Table 7.

As shown in Tables 4-7, for the air transport industry and the road transport industry, the Hausman test results indicate that the individual fixed-effects model should be selected for model regression analysis. For the water transport industry, the $P$ value of the model is greater than
TABLE 7: Hausman test results of the measurement model of each subindustry.

\begin{tabular}{lccc}
\hline Industry & Detection value & Model (3) & Model (4) \\
\hline \multirow{4}{*}{ Air transport industry } & Chi-sq. & 22.038 & 14.216 \\
& Prob. & 0.0002 & 0.0066 \\
& Result & $\mathrm{FE}$ & $\mathrm{FE}$ \\
& Chi-sq. & 8.075 & 19.757 \\
Road transport industry & Prob. & 0.0089 & 0.0006 \\
& Result & $\mathrm{FE}$ & $\mathrm{FE}$ \\
Water transport & Chi-sq. & 1.966 & 7.231 \\
industry & Prob. & 0.7420 & 0.1242 \\
& Result & $\mathrm{RE}$ & $\mathrm{RE}$ \\
\hline
\end{tabular}

Note. Chi-sq. means the chi-square value, FE means the fixed-effects model, and RE means the random effects model.

0.05. The effect model is subjected to regression analysis, and the specific model regression results are shown in Table 8.

\section{Discussion}

From the analysis of the results in Tables 4-7, the following conclusions can be drawn:

(1) First, from the perspective of technological progress, the relationship between technological progress in the air transport industry and the proportion of personnel with a college degree or above is positively significant at the $5 \%$ significance level, and the coefficient of the technological progress index is 0.394, which is much larger than the other two industries; the road transport industry technological progress and the proportion of employees with a college degree and above are positively significant at a significance level of $10 \%$, and the proportion of nonproduction employees is positively significant at a significance level of 5\%; In the water transportation industry, technological progress has not had a significant impact on the employment skill structure. It can be seen from the nature of the industry that the air transportation industry is an industry that places great emphasis on safety and stability, so the requirements for employee skills are also extremely strict. At the same time, the air transportation 
TABLE 8: Regression analysis results of each logistics segment industry model.

\begin{tabular}{lccc}
\hline Research study variables & Subdivided industry & $\begin{array}{c}\text { Model (3) } \\
\text { Proportion of employees with } \\
\text { college degree and above (Y1) }\end{array}$ & $\begin{array}{c}\text { Model (4) } \\
\text { Percentage of nonproductive } \\
\text { personnel }(Y 2)\end{array}$ \\
\hline & Air transport industry & $0.592990^{* * *}$ & $0.470530^{* * *}$ \\
Constant $C i$ & Road transport industry & $0.343011^{* * *}$ & $0.337696^{* * *}$ \\
& Water transport industry & $0.391089^{* * *}$ & $0.265077^{* * *}$ \\
Skill improved $X 1 i$ & Air transport industry & $0.394020^{* *}$ & -0.132142 \\
& Road transport industry & $0.096592^{*}$ & $0.284305^{* *}$ \\
Enterprise size $X 2 i$ & Water transport industry & 0.044584 & 0.011655 \\
& Air transport industry & $0.323837^{*}$ & $-0.318394^{* * *}$ \\
Training structure $X 3 i$ & Road transport industry & $1.499344^{*}$ & 0.488669 \\
& Water transport industry & $0.487271^{* *}$ & -0.553805 \\
Salary structure $X 4 i$ & Air transport industry & $0.036073^{*}$ & -0.103128 \\
& Road transport industry & 0.389798 & 0.408890 \\
& Water transport industry & 0.242129 & $-0.787076^{* * *}$ \\
& Air transport industry & 0.130568 & 0.020490 \\
& Road transport industry & $3.757804^{* * *}$ & $-2.709841^{* *}$ \\
\hline
\end{tabular}

Note. $X 1 i, X 2 i, X 3 i$, and $X 4 i$ in the table represent three different subindustries corresponding to technological progress, enterprise scale, training structure, and work structure variables, respectively. For example, $X 11$ represents the technological progress of the air transport industry, where $i=1,2,3$. In addition, ${ }^{* * *}$ and ${ }^{* * *}$ indicate the significance level of $10 \%, 5 \%$, and $1 \%$, respectively.

industry is a large state-owned monopoly industry with a high level of personnel management. In addition, the professional classification of the air transportation industry includes a large number of engineering and information technology personnel. It can be seen that the air transportation industry has a greater demand for highly skilled personnel and management requirements. For the road transportation industry and water transportation industry, it is mainly based on skill research and job title evaluation, and the requirements for academic qualifications are not very high. There is even no classification of technical, engineering, or information personnel in many companies, especially in the water transportation industry.

(2) From the perspective of enterprise scale, the enterprise scale of each subindustry has a positive correlation with the proportion of employees with college degree and above, and they are significant at the significance levels of $10 \%, 10 \%$ and $5 \%$, respectively. In addition, the technological progress of the air transport industry is negatively correlated with the proportion of nonproductive personnel at the $1 \%$ significance level. To sum up, the expansion of the scale of air transportation, road transportation, and water transportation companies is conducive to increasing the proportion of highly educated employees in the enterprise, and the role of road transportation is the most obvious. The expansion of the scale of the air transport industry will reduce the proportion of nonproductive employees in the company. This may be because with the continuous development of the company, the number of nonproductive personnel has increased to a certain extent, but the growth rate of personnel is still relatively not very obvious.
Although China's logistics industry has developed rapidly in recent years, the scale of the company has continued to expand, and the equipment, R\&D investment, human capital investment, resource allocation, and management level have all been greatly improved, but overall there is still a big gap compared with the logistics level of developed countries such as the United States in lots of aspects, such as insufficient output efficiency, unbalanced overall quality of employees, older employment age, and more productive front-line employees and so forth. Therefore, it can be considered that although the scale of enterprises continues to increase, there is still a large shortage of supply and demand for highskilled management talents in the logistics industry.

(3) From the perspective of training structure, the training structure of the air transport industry and the proportion of personnel with a college degree or above are positively significant at the significance level of $10 \%$, indicating that the increase in the investment in personnel training in the air transport industry will have positive impacts on the increase in the proportion of personnel with education qualifications and above. For the road transportation industry, the regression results of the model are not significant, indicating that the road transportation industry's investment in skills training is not significantly related to the increase in the proportion of highly educated or nonproductive personnel. In addition, there is no significant correlation between the training structure of the water transportation industry and the proportion of personnel with a college degree or above, but the water transportation industry is negatively correlated with the proportion of nonproductive personnel at the $1 \%$ significance level. Investing in training will significantly increase 
the proportion of production personnel. From the perspective of the professional structure of personnel in the water transport industry, it mainly includes engineering and technical personnel, management personnel, transport crews, political workers, and other categories, and the proportion of crew members is much larger than that of management and technical personnel, and even some companies do not have technology personnel classification. It can be seen that the water transportation industry pays more attention to the operation training of production labor, which is conducive to the improvement of input and output efficiency on the one hand and can reduce the company's employment costs on the other hand.

(4) From the perspective of wage structure, with the exception of the air transportation industry, there is no significant correlation between the variables, and the relationship between the variables in the other two industries shows a significant correlation. Among them, the wage structure of the road transportation industry not only has a positive correlation with the proportion of employees with a college degree or above at a significant level of $1 \%$ but also has a negative correlation with the proportion of nonproductive personnel at a significant level of 5\%. Besides, the wage structure of the water transportation industry has a significant positive correlation with the proportion of employees with a college degree or above and the proportion of nonproductive personnel at a significant level of $1 \%$. This shows that the increase in employee wages in the road and water transportation industry will significantly increase the proportion of high-educated employees in the company.

\section{Conclusion}

This article mainly analyzes the relationship between technological progress and employment structure in China's logistics industry and analyzes the industry characteristics reflected in the level of technological progress and employment structure in various subsectors of the logistics industry, and then it explores the adaptability between employment structures and level of technological progress. On the whole, technological progress in China's logistics industry will have a significant positive impact on the structure of employment skills. With the continuous improvement of the level of information technology, both the proportion of personnel with a college degree or above and the proportion of nonproduction personnel are showing an increasing trend. Secondly, the expansion of the scale of Chinese logistics companies will significantly increase the relative demand for highly educated personnel, but it will also inhibit the growth of the proportion of nonproductive personnel. That is, the larger the scale of the company, the greater the proportion of personnel with a college degree or above and the more decreases of the relative proportion of nonproduction personnel. Finally, the increase in the wage level of employees in China's logistics industry will significantly increase the proportion of nonproductive personnel in the company, but it will not have a significant impact on the increase in personnel with a college degree or above.

The contributions of this article are as follows: first, this article is an industry-specific microresearch, which bridge the research gap. At present, most of the literature on the relationship between technological progress and employment is at the macrolevel, and the research objects are mainly industry or manufacturing. There is very little research in discussing the relationship between technological progress and the structure of employment skills in the context of technological progress, let alone on the logistics industry. Therefore, starting from a microperspective, this article has conducted in-depth research on the panel data of 49 listed companies in Chinese logistics industry to make up for this research gap. Second, this essay has innovatively enriched the measurement system of technological progress indicators. It can be found that most scholars directly choose a single indicator or the arithmetic average of two indicators to replace technological progress for analysis, but because there are many factors that reflect technological progress in the logistics industry, such choice will ignore some important details and characteristics of subindustry, which inevitably causes large errors in the research results. This article not only selects net fixed assets, total employee wages, and operating costs as input indicators from the perspective of machinery and equipment, human capital investment, and management and operation but also takes the main business income as the output indicators to measure the technological progress index of the logistics industry and use it to represent technological progress. In this way, it greatly reflects the characteristics of the industry and increases the accuracy of the research results.

However, there are also some limitations in the research. To be more specific, this article uses data from listed companies in the logistics industry. However, there are certain differences in the data classification rules for the employment structure of listed companies in the logistics industry. Some companies do not have the classification of production and technical employees, and they have different subindustries, which will inevitably affect the results of the research to a certain extent and cause certain errors. Therefore, future research can consider making more improvements in this area to make up for the limitations of this research.

\section{Data Availability}

The data used to support the findings of this study are available from the corresponding author upon request.

\section{Conflicts of Interest}

The authors declare there are no conflicts of interest regarding the publication of this paper.

\section{Acknowledgments}

This article was supported by theGuangdong Province Philosophy and Social Science Planning Project, "Research 
on the Optimization of Labor Skills Structure of China's Service Industry under the New Normal Based on the Perspective of Technological Progress" (GD15CYJ04); Guangdong Province General University Characteristic Innovation Project, "Technical Progress Direction and Labor Skills of China's Service Industry under the New Normal Research on Structural Optimization" (15T12); 2017 Guangdong Undergraduate Higher Education Teaching Reform Project, "Research on Logistics Professional Course System Based on Service Science"; and the Key Scientific Research Projects of Universities in Guangdong Province (2018WTSCX034).

\section{References}

[1] S. Xiong and Y. Zhu, "The experience of technological progress and employment growth in the eastern region," Contemporary Economy, vol. 36, no. 12, pp. 100-101, 2008.

[2] M. Jiang, "Analysis of the impact of technological progress on employment," Science and Technology Management Research, vol. 40, no. 1, pp. 70-73, 2007.

[3] L. Bo and J. Wen, "The employment effect of technological progress in China's industrial sector," Economic Developments, vol. 61, no. 10, pp. 34-37, 2010.

[4] I. Srour, E. Taymaz, and M. Vivarelli, Skill-Biased Technological Change and Skill-Enhancing Trade in Turkey: Evidence from Longitudinal Microdata, IZA-Institute of Labor Economics, Bonn, Germany, 2013.

[5] R. Rogerson, J. P. Kaboski, and F. Buera, "Skill-biased structural change and the skill premium," in Proceedings of the 2015 Meeting Papers, Society for Economic Dynamics, Warsaw, Poland, 2015, https://ideas.repec.org/p/red/sed015/895. html\#download.

[6] E. Berman, J. Bound, and S. Machin, "Implications of skillbiased technological change: international evidence," The Quarterly Journal of Economics, vol. 113, no. 4, pp. 1245-1279, 1998.

[7] A. Spitz-Oener, "Technical change, job tasks, and rising educational demands: looking outside the wage structure," Journal of Labor Economics, vol. 24, no. 2, pp. 235-270, 2006.

[8] J. Kaplan, Humans Need Not Apply: A Guide to Wealth and Work in the Age of Artificial Intelligence, Yale University Press, London, UK, 2015.

[9] Q. Zhu and M. Li, "Research on countermeasures for artificial intelligence, technological progress and labor structure optimization," Science and Technology Progress and Countermeasures, vol. 35, no. 6, pp. 36-41, 2018.

[10] J. Mincer and S. Danninger, "Technology, unemployment and inflation," NBER Working Paper, National Bureau of Economic Research, Cambridge, MA, USA, 2000.

[11] D. Acemoglu, "Changes in unemployment and wage inequality: an alternative theory and some evidence," American Economic Review, vol. 89, no. 5, pp. 1259-1278, 1999.

[12] L. F. Katz and K. M. Murphy, "Changes in relative wages, 1963-1987: supply and demand factors," The Quarterly Journal of Economics, vol. 107, no. 1, pp. 35-78, 1992. 